\title{
Alcoholmeter as a Simple and Accessible Way for Ethanol Determination in Alcohol-Based Hand Sanitizers
}

\author{
Priscila L. S. Estevão, ${ }^{a}$ Franciely G. Colodi, ${ }^{b}$ Lucas C. L. do Carmo, ${ }^{\circledR b}$ \\ Maria de Fátima C. Santos, ${ }^{c}$ Andersson Barison, ${ }^{c}$ Caroline R. M. D'Oca, ${ }^{c}$ \\ Noemi Nagata ${ }^{a}$ and Rilton A. de Freitas ${ }^{\circledR * b}$ \\ ${ }^{a}$ Grupo de Análise Química e Quimiometria (GAQQ), Departamento de Química, \\ Universidade Federal do Paraná(UFPR), 81531-980 Curitiba-PR, Brazil \\ ${ }^{b}$ Laboratório de Biopolímeros (BioPol), Departamento de Química, \\ Universidade Federal do Paraná (UFPR), 81531-980 Curitiba-PR, Brazil \\ 'Laboratório de Ressonância Magnética Nuclear, Departamento de Química, \\ Universidade Federal do Paraná (UFPR), 81531-980 Curitiba-PR, Brazil
}

\begin{abstract}
Expensive and complex methodologies are available to determine the ethanol concentration in alcohol gel samples. The aim of this article was to demonstrate that alcoholmeter could be used as an alternative method to determine ethanol in gel formulations. Alcohol gel samples were produced using: hydroxypropylmethylcellulose (HPMC), hydroxyethylcellulose (HEC) and Carbopol $940^{\circ}$ (CBP). A factorial design was performed to evaluate the interaction between the ethanol concentration, glycerin and polymer contents in the samples in the recovery data of the ethanol content. Rheological analyses were also performed to identify the limiting factors to ethanol quantification. All the results were compared to high resolution magic angle spinning nuclear magnetic resonance (HR-MAS NMR) as a reference methodology. The results demonstrated that the alcoholmeter could be used to determine alcohol concentration, moreover the level of polymer HEC or HPMC, glycerin and ethanol has no effect in the determination. Yield stress, and not viscosity or flow index, appeared as the limiting factor to the use of alcoholmeter in non-acidified CBP samples. Acidification appears to be mandatory to determination of ethanol concentration in CBP samples. It was possible to achieve an inexpensive, handy and fast methodology to quantify alcohol in gelled samples, in the range of concentrations used in this article.
\end{abstract}

Keywords: ethanol quantification, alcoholmeter, HR-MAS NMR, carbopol, HPMC, HEC

\section{Introduction}

Coronavirus disease 2019 (COVID-19) brought the world into a public health emergency. The pandemic was established by the high transmission rate of the virus of severe acute respiratory syndrome coronavirus 2 (SARS-CoV-2). Therefore, beyond social distancing and use of protective masks, the disinfection of surfaces, objects and hands became the main way to stop and control virus spreading away. ${ }^{1,2}$

In this context, the ethanol-based hand sanitizers are indispensable to disinfection. Ethanol presents a very low cutaneous toxicity to humans and is an effective antiseptic and disinfectant at 60 to $80 \mathrm{wt}$ \% solutions in water. Indeed,

*e-mail: rilton@ufpr.br
$70 \mathrm{wt} . \%$ ethanol is able to inactivate bacterial spores via inner membranes permeation. It is well known that ethanol diluted in water causes accelerated microbiota's protein denaturation, leading to the potent virucidal property of hydroalcoholic mixtures against the enveloped viruses as human immunodeficiency virus (HIV), influenza, herpes simplex virus 1 and SARS-CoV-2., ${ }^{3,4}$

The Brazilian National Health Surveillance Agency (ANVISA) predicts hydroalcoholic mixtures from 70.0 to 75.0 wt.\% for disinfection. ${ }^{5,6} \mathrm{Gel}$ formulations for antiseptic purpose must contain from 68.25 to $71.75 \mathrm{wt} . \%$ of ethanol, besides water, carbomer (CBP) as thickener and triethanolamine to $\mathrm{pH}$ adjustment. Glycerin also might be added as emollient. Furthermore, cellulose derivatives such as hydroxypropylmethylcellulose (HPMC) and hydroxyethylcellulose (HEC) stand out as alternative 
thickening agents, which have been pursued to fill the lack of these products due to CBP's disappearance from the international market, associated with the extensive consume of hand antiseptics during the COVID-19 pandemic..$^{5-7}$

Because the international public health emergency, ANVISA eased proceedings to production and commercialization of ethanol-based hand sanitizers. However, the disobliged product registration led to irregular manufacturers and increased seizures of nonconforming products, which bring risks to consumers and public health. The regulatory agencies must be able to detect nonconformities in order to protect consumers and attest products specifications. ${ }^{8}$

Reachable and reliable methods are required to determine the ethanol content in gel hand antiseptics. Nuclear magnetic resonance and infrared spectroscopies, as well as gas chromatography (GC), can measure ethanol contents, although they also demand longer time of analysis, expensive equipment and specialized human resources. ${ }^{9-11}$ Although specific gravity methods including alcoholmeter, hydrometer or pycnometer measurements demand less time and cheaper accessories, they are usually applied only to liquid sanitizers containing ethanol. ${ }^{12}$

Therefore, the aim of this work was to verify if alcoholmeter could be able to determine the ethanol content of antiseptic gel formulations, as a handy, faster and cheaper method to attest ethanol concentration specifications. The components thickener, emollient and ethanol were evaluated to reveal its effects in formulation, and in the recovery data of the ethanol content $(\%)$, via $2^{3}$ full factorial design. Two commercial cellulose ether derivatives, HEC and HPMC, were tested in comparison to a reference of CBP. The ethanol concentration in alcohol-based hand sanitizers were evaluated by alcoholmeter measurements and by nuclear magnetic resonance (NMR) spectroscopy, used as a reference method.

\section{Experimental}

\section{Materials}

Ethanol-based hand sanitizers compounding were prepared with three distinct commercial polymers: KOLAGEL Plus ${ }^{\oplus}$ (HPMC), KOLAGEL 30KB ${ }^{\odot}$ (HEC), both from MC Química, São Paulo, Brazil, and Carbomer Carbopol $940^{\circ}$ (CBP), from Lubrizol, Wickliffe, USA. Ethanol (> 96 Gay-Lussac degree $\left({ }^{\circ} \mathrm{GL}\right)$ ) and glycerin (99.5\%) were acquired from Álcool Santa Cruz Ltda, Guarulhos, Brazil and Proc9 Indústria Ltda, Canoas, Brazil, respectively. Purified water was obtained from a reverse osmosis system (Gehaka OS10LXE, São Paulo, Brazil) and conductivity of $0.05 \mu \mathrm{S} \mathrm{cm}^{-1}$. All other chemicals and reagents used were of analytical grade.

\section{Experimental design}

A $2^{3}$ experimental full factorial design (one for each mentioned polymer) was carried out to evaluate the effect of the contents (wt.\%) of ethanol, glycerin and polymer in the data of recovery of the ethanol content $(\%)$. To estimate the deviation of the effect, the center point was performed in triplicate (Table 1).

Table 1. Conditions employed in the $2^{3}$ factorial design for HPMC, HEC and CBP polymers

\begin{tabular}{lcccc}
\hline \multirow{2}{*}{ Polymer } & Factor / wt. $\%$ & \multicolumn{3}{c}{ Level } \\
\cline { 3 - 5 } & glycerin & 0.500 & 1.00 & 1.50 \\
\multirow{3}{*}{ HPMC } & HPMC & 0.500 & 0.750 & 1.00 \\
& ethanol & 60.0 & 70.0 & 80.0 \\
\hline \multirow{3}{*}{ HEC } & glycerin & 0.500 & 1.00 & 1.50 \\
& HEC & 0.500 & 0.750 & 1.00 \\
& ethanol & 60.0 & 70.0 & 80.0 \\
\multirow{3}{*}{ CBP } & glycerin & 0.500 & 1.00 & 1.50 \\
& CBP & 0.350 & 0.500 & 0.650 \\
& ethanol & 60.0 & 70.0 & 80.0 \\
\hline
\end{tabular}

HPMC: hydroxypropylmethylcellulose; HEC: hydroxyethylcellulose; CBP: carbomer Carbopol $940^{\circ}$.

In each experiment, $500 \mathrm{~g}$ formulations were prepared starting from alcohol with apparent alcoholic degree of $96{ }^{\circ} \mathrm{GL}$. The ethanol concentration in liquid samples was measured by alcoholmeter (Gay-Lussac \& Cartier alcoholmeter, Rivaterm 7190-13, São Paulo, Brazil) and converted to wt. $\%$ at $15{ }^{\circ} \mathrm{C}$ using Tables A.1 and B.1 from the Brazilian National Pharmacopeia. ${ }^{5}$ The procedure for preparation of HPMC and HEC alcohol gels consisted of adding half the total amount of ethanol, required for each sample, to the total amount of water, polymer, and glycerin in a $600 \mathrm{~mL}$ beaker under constant mechanical stirring at $100 \mathrm{rpm}$ (Fisatom 713, São Paulo, Brazil) for $1 \mathrm{~min}$. Then an aqueous solution of $\mathrm{NaOH} 5.0$ wt.\% was added until pH 6.0 and the dispersions were kept under mechanical stirring for $5 \mathrm{~min}$. Finally, the remaining ethanol was added and the dispersions were stirred for more $5 \mathrm{~min}$. The $\mathrm{pH}$ measurements (pHmeter MS Tecnopon mPA-210, Piracicaba, Brazil) were performed on gels diluted (1:10) in purified water.

CBP formulations were prepared by adding respective quantity of polymer, slowly and under vigorous mechanical stirring, to the total water, glycerin, and ethanol. After complete dispersion, $\mathrm{pH}$ was adjusted with a hydroalcoholic triethanolamine $50 \mathrm{wt} . \%$ solution. 
Furthermore, all formulations were analyzed by alcoholmeter and NMR spectroscopy for determination of ethanol content (wt.\%). The recoveries (R) were used as responses to estimate the effects of the factorial design, considering ethanol content estimated $\left(\mathrm{C}_{0}, \mathrm{wt} . \%\right)$ by both methods and the expected concentration $\left(\mathrm{C}_{\mathrm{e}}\right.$, wt.\%), i.e., the levels of factors (equation 1). The recoveries were evaluated in the software Statistica. ${ }^{13}$

$\mathrm{R}(\%)=\frac{\mathrm{C}_{\mathrm{o}}}{\mathrm{C}_{\mathrm{e}}} \times 100$

\section{Alcoholmeter method}

HPMC and HEC formulations were transferred to a $250 \mathrm{~mL}$ graduated cylinder and the alcoholmeter was dipped slowly into the gel until the $90{ }^{\circ} \mathrm{GL}$ marking, avoiding contact with the bottom and walls. Then, after equilibrium for $15 \mathrm{~min}$, the scale of the alcoholmeter was read. For CBP formulations it was not possible to measure the alcoholic degree using this method due to the impact of rheological parameters of the samples. To overcome this, an acidification step was performed by adding $1.5 \mathrm{~g}$ of aqueous solution of $1.00 \mathrm{~mol} \mathrm{~L}^{-1} \mathrm{HCl}$ to each $200 \mathrm{~g}$ of gel, disrupting the gel structure. The dilution promoted by acidification was considered in the recovery estimated for the evaluation of the factorial design effects. To analyze the influence of the dilution, experiments were performed using $0.3 \mathrm{~g}$ of a $5.00 \mathrm{~mol} \mathrm{~L}^{-1} \mathrm{HCl}$ aqueous solution only to $0.65 \mathrm{wt} . \%$ CBP formulations. After alcoholmeter equilibrium, the ${ }^{\circ} \mathrm{GL}$ was read as described previously for liquid ethanol samples. Temperature was recorded with a thermometer (Incoterm 206119/15, Porto Alegre, Brazil) and the ${ }^{\circ} \mathrm{GL}$ measurements were corrected to wt. $\%$ at $15{ }^{\circ} \mathrm{C} .{ }^{5}$

\section{Nuclear magnetic resonance (NMR) method}

HPMC and HEC hand sanitizer formulations (around three drops) were transferred into 4-mm high resolution magic angle spinning (HR-MAS) NMR rotors without any addition of deuterated solvents and then submitted to ${ }^{1} \mathrm{H}$ HR-MAS NMR analysis. The samples prepared with CBP were acidified as performed in the measurements using alcoholmeter only for comparative purposes since the dilution is not required for NMR analysis. The ${ }^{1} \mathrm{H}$ quantitative NMR (qNMR) HR-MAS measurements were performed at room temperature on a Bruker AVANCE NMR spectrometer (Rheinstetten, Germany), operating at 9.4 Tesla, observing ${ }^{1} \mathrm{H}$ nuclei at $400.13 \mathrm{MHz}$. The instrument was equipped with a three channel $\left({ }^{1} \mathrm{H},{ }^{13} \mathrm{C}\right.$ and $\left.{ }^{15} \mathrm{~N}\right)$ 4-mm HR-MAS NMR probe with an actively shielded magic angle gradient. The spectra were acquired directly from neat samples, by using single $90^{\circ}$ excitation pulse, $10 \mathrm{~s}$ relaxation delay (d1), 4 dummy scans (ds), 8 transients (ns), $6.49 \mathrm{~s}$ acquisition time, $64 \mathrm{k}$ data points distributed over a $5050 \mathrm{~Hz}$ spectral width. The spectra were processed by the application of an exponential multiplication free induction decay (FID) with a line broadening factor of $0.3 \mathrm{~Hz}$, followed by Fourier transform with zero filling by a factor of 2 . The samples were spun at $5 \mathrm{kHz}$ at the magical angle $\left(\theta=54.74^{\circ}\right)$ and the lock system was turned off.

The ethanol contents were determined by measuring the relationship between the signal areas from ethanol at ca. 1.18 and ca. 3.62 and water at ca. $4.90 \mathrm{ppm}$, which were normalized to $100 \%$.

\section{Viscosity effect in the alcoholmeter method}

In order to evaluate the effect of polymers concentration, and consequently, the effect of the different viscosities in the ethanol content determination by alcoholmeter, tree tests with different contents (wt.\%) of each polymer were conducted in triplicate. Dispersions of $250 \mathrm{~g}$ of alcohol gel 70 wt.\% with $1.00 \mathrm{wt} . \%$ of glycerin were prepared as aforesaid for each polymer. The investigated polymer contents in wt.\% were $0.750,1.00$, and 1.25 for HPMC; $0.750,1.50$, and 2.00 for HEC, and 0.350, 0.500, and 0.650 for CBP. The ethanol content estimated by NMR and alcoholmeter methods were evaluated by a two-way analysis of variance (ANOVA) in the software Statistica, ${ }^{13}$ also considering the polymer concentration. In addition, $\mathrm{pH}$ and viscosity of the preparations were measured.

\section{Rheological measurements}

Single point viscosity measurements were made at Brookfield DV-III + rheometer (Warnford, England) with a No. 4 spindle at 20 RPM and temperature range of $25 \pm 1{ }^{\circ} \mathrm{C}$. Temperature was controlled with a water circulator C10 (Thermo Haake, Texas, USA) and water was pumped through a jacketed glass beaker with capacity of $250 \mathrm{~mL}$. Prior to measurement, approximately $200 \mathrm{~mL}$ of the sample were transferred to the jacketed beaker and left to rest for $60 \mathrm{~s}$ to reach temperature equilibrium and viscosity was recorded once the value measured stabilized.

Viscoelastic properties of the prepared formulas were characterized using a HAAKE ${ }^{\mathrm{TM}}$ RheoStress ${ }^{\mathrm{TM}} 1$ Rheometer (Thermo Scientific, Waltham, USA) with temperature controlled by a Haake DC 30 (Thermo Haake, Texas, USA) water circulator in the range of $25.0 \pm 0.5^{\circ} \mathrm{C}$. The geometry used to perform the experiments was a cone with diameter of $60 \mathrm{~mm}$, angle of $2^{\circ}$ and truncation gap of $0.105 \mathrm{~mm}$. 
Shear stress $(\tau)$ oscillatory sweeps were performed with a constant oscillating frequency of $1 \mathrm{~Hz}$ from 0.1 to $100 \mathrm{~Pa}$ in log-spaced increments to determine elastic $\left(G^{\prime}\right)$ and viscous (G”) moduli within the linear viscoelasticity range. Frequency sweeps were performed in a stress within the linear viscoelasticity range from 0.1 to $10 \mathrm{~Hz}$ to verify the polymer dispersions frequency dependency. The formulas were also characterized in rotational rheometer with flow curves performed in a shear rate $(\dot{\gamma})$ range from 0.1 to $60 \mathrm{~s}^{-1}$ in a stepwise fashion in the same conditions as oscillatory measurements.

\section{Results and Discussion}

Factorial design to evaluate the influence of ethanol, glycerin and polymer in alcohol quantification in gelled samples

The recovery values estimated by NMR and alcoholmeter methods, and the viscosities in each test of the factorial design, for the three different polymers, were summarized in Table 2. The effects of the factors in the recoveries (R) obtained by the alcoholmeter method were estimated by the software Statistica ${ }^{13}$ and can be observed in the Pareto chart for each polymer tested (Figure 1). The values of $\mathrm{pH}$ observed for HPMC and HEC preparations, after dilution in water, were $6.1 \pm 0.1(n=11)$ and $5.8 \pm 0.1(n=11)$, respectively. The CBP, after dilution in water, presented a final $\mathrm{pH}$ of $4.4 \pm 0.4(\mathrm{n}=11)$, and after acidification, for ethanol quantification using alcoholmeter, the $\mathrm{pH}$ was ca. 3.3. Representative ${ }^{1} \mathrm{H}$ HR-MAS NMR spectra of the different polymers and concentrations were presented in the Supplementary Information section, Figures S1, S2 and S3, respectively for HPMC, HEC and CBP samples.

The estimated effects for the factorial design can be compared with the respective standard deviation (SD) of the center point associated with $t_{\text {student }}$ for the triplicate, considering $95 \%$ of confidence level $\left(t_{95 \%} 4.303\right.$ for two degrees of freedom). Thereby, the effects superior to the $\mathrm{SD} \times t_{\text {student }}$ were considered statistically significant. ${ }^{14}$ The values of $\mathrm{SD} \times t_{\text {student }}$ obtained in each design were presented in the Table 2 and were indicated by the dotted line in the Pareto charts (Figure 1).

As observed in Figure 1, none of the factors had significant effects in the response estimated by the method of alcohol quantification using an alcoholmeter for all polymers tested, even with an expressive variation of viscosity (Table 2 ). The values of effect considering the recoveries obtained by NMR support these observations. Also, it was not possible to estimate the ethanol content directly in CBP using alcoholmeter, without a previous sample acidification, even for samples with viscosities (a)

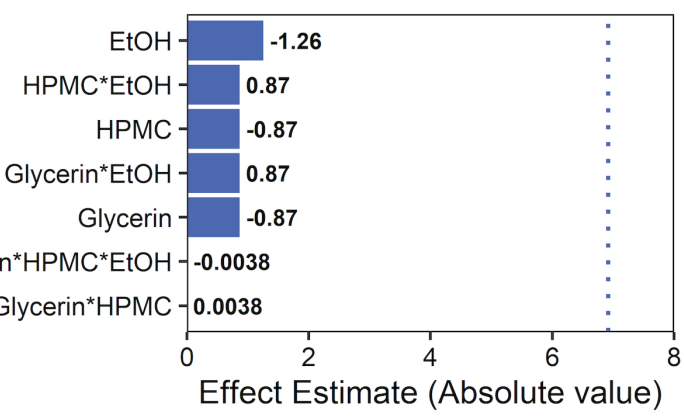

(b)
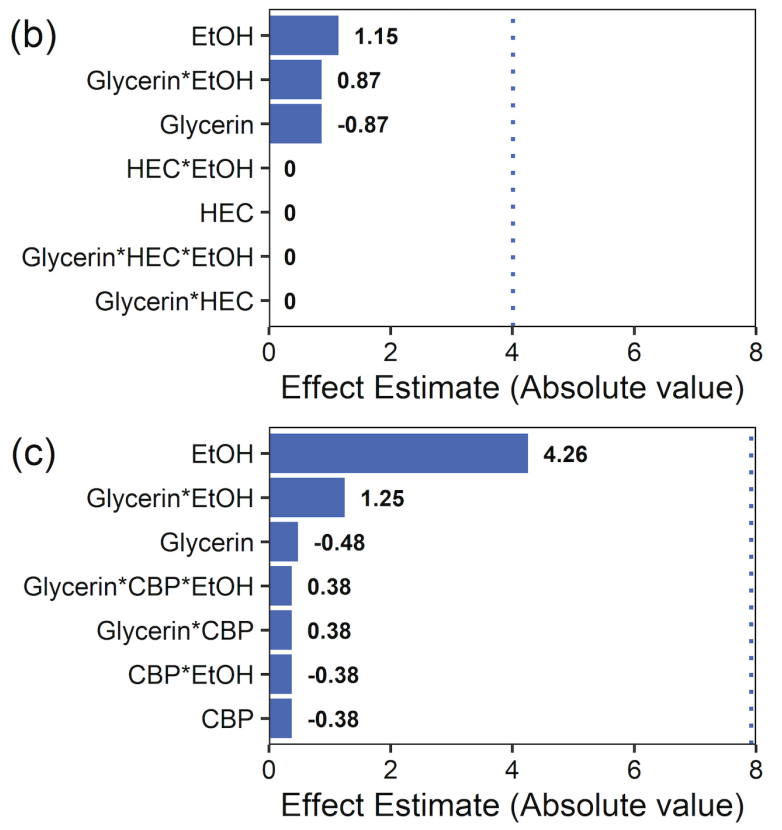

Figure 1. Pareto chart effects for hydroxypropylmethylcellulose (HPMC) (a), hydroxyethylcellulose (HEC) (b), and carbomer Carbopol $940^{\circ}$ CBP (c) from a $2^{3}$ factorial design. EtOH means ethanol.

values $<1000 \mathrm{mPa}$ s. Therefore, it was possible to infer that viscosity was not a relevant factor in the estimation of the ethanol content by the proposed alcoholmeter method for CBP samples. Nevertheless, rheological properties of the samples might be discussed in other terms than only viscosity, contributing to the discussion of why the alcoholmeter was not reliable to produce accurate results for CBP samples without acidification.

Evaluation of the viscosity, yield stress and viscoelastic behavior of alcohol in gel formulations

Although the viscosity was not a relevant factor in determining the alcoholic content of HEC and HPMC formulations, a difficulty arises during alcohol content determination of CBP formulas. This has to do not only with viscosity but also with the type of the gelled structure created when in dispersion. Unlike the cellulose derivatives used, the CBP polymer may form a structured network that presents solid-like properties at low amplitude shear stress. ${ }^{15}$ 
Table 2. Viscosities values and recoveries estimated by alcoholmeter and NMR for HPMC, HEC, and CBP using $2^{3}$ factorial design

\begin{tabular}{|c|c|c|c|c|c|c|c|c|c|c|c|c|}
\hline \multirow{3}{*}{ Test } & \multirow{2}{*}{\multicolumn{3}{|c|}{ Factor }} & \multicolumn{9}{|c|}{ Polymer type } \\
\hline & & & & \multicolumn{3}{|c|}{ HPMC } & \multicolumn{3}{|c|}{ HEC } & \multicolumn{3}{|c|}{$\mathrm{CBP}$} \\
\hline & $\begin{array}{c}\text { Glycerin / } \\
\text { wt. } \%\end{array}$ & $\begin{array}{c}\text { Polymer / } \\
\text { wt. } \%\end{array}$ & $\begin{array}{c}\text { Ethanol / } \\
\text { wt.\% }\end{array}$ & $\mathrm{R}_{\text {Alc. }}{ }^{\mathrm{a}} / \%$ & $\mathrm{R}_{\mathrm{NMR}}^{\mathrm{b}} / \%$ & $\begin{array}{c}\eta^{\mathrm{c}} / \\
(\mathrm{mPa} \mathrm{s})\end{array}$ & $\mathrm{R}_{\text {Alc. }}{ }^{\mathrm{a}} / \%$ & $\mathrm{R}_{\mathrm{NMR}}{ }^{\mathrm{b}} / \%$ & $\begin{array}{c}\eta^{\mathrm{c}} / \\
(\mathrm{mPa} \mathrm{s})\end{array}$ & $\mathrm{R}_{\text {Alc. }}{ }^{\mathrm{a}} / \%$ & $\mathrm{R}_{\mathrm{NMR}}^{\mathrm{b}} / \%$ & $\begin{array}{c}\eta^{\mathrm{d} /} \\
(\mathrm{mPa} \mathrm{s})\end{array}$ \\
\hline 1 & - & - & - & 102.3 & 101.7 & $<1000$ & 100.6 & 104.1 & $<1000$ & 97.8 & 97.9 & 3930 \\
\hline 2 & + & - & - & 100.6 & 103.8 & $<1000$ & 98.8 & 102.0 & $<1000$ & 96.1 & 96.6 & 3200 \\
\hline 3 & - & + & - & 100.6 & 102.2 & 5400 & 100.6 & 96.9 & 1200 & 97.8 & 99.4 & 7230 \\
\hline 4 & + & + & - & 98.8 & 97.8 & 5540 & 98.8 & 103.2 & 1140 & 96.1 & 100.1 & 10600 \\
\hline 5 & - & - & + & 99.3 & 103.0 & $<1000$ & 100.8 & 100.3 & $<1000$ & 101.6 & 98.0 & $<1000$ \\
\hline 6 & + & - & + & 99.3 & 103.0 & $<1000$ & 100.8 & 100.8 & $<1000$ & 101.6 & 98.9 & $<1000$ \\
\hline 7 & - & + & + & 99.3 & 103.2 & $<1000$ & 100.8 & 100.5 & $<1000$ & 100.1 & 98.5 & 2540 \\
\hline 8 & + & + & + & 99.3 & 102.0 & $<1000$ & 100.8 & 101.0 & $<1000$ & 101.6 & 98.8 & 4340 \\
\hline $\mathrm{CP}$ & 0 & 0 & 0 & 98.6 & 102.2 & 2500 & 101.8 & 102.2 & $<1000$ & 99.3 & 101.5 & 6900 \\
\hline $\mathrm{CP}$ & 0 & 0 & 0 & 101.8 & 100.5 & 1590 & 100.2 & 100.8 & $<1000$ & 96.1 & 101.3 & 8090 \\
\hline $\mathrm{CP}$ & 0 & 0 & 0 & 100.2 & 103.3 & 2340 & 101.8 & 101.9 & $<1000$ & 96.1 & 102.0 & 7340 \\
\hline \multicolumn{4}{|c|}{ Center point $(\mathrm{CP})$ mean } & 100.2 & 102.0 & 2143 & 101.2 & 101.6 & - & 97.2 & 101.6 & 7443 \\
\hline \multicolumn{4}{|c|}{ CP standard deviation (SD) } & 1.6 & 1.4 & 486 & 0.9 & 0.8 & - & 1.8 & 0.3 & 601 \\
\hline \multicolumn{4}{|c|}{$\mathrm{SD} \times t_{\text {value }(95 \% \text { of confidence level, } \mathrm{n}=3 \text { ) }}$} & 6.9 & 6.0 & 2090 & 4.0 & 3.2 & - & 7.9 & 1.4 & 2589 \\
\hline
\end{tabular}

In Figure 2a it is possible to observe that for $\mathrm{CBP}$, within the linear viscoelasticity region, the elastic modulus ( $\left.G^{\prime}\right)$ is several times larger than viscous modulus (G"), indicating such as a solid-like viscoelastic structure. Different rheological behaviors were observed in the mechanical spectra of HPMC and HEC formulations. Whilst HPMC preparation exhibited a smaller range where G' $>$ G', HEC formulation showed predominance of G" over the entire range of amplitude stresses, characterizing the latter as a viscoelastic liquid-like structure.

In Figure $2 b$ it is possible to observe that the gelled CBP dispersion showed little to any frequency dependency, with G' predominance in the range of frequencies observed. For HPMC formulation it is possible to observe that G' and G" were overlapped, which indicates that this material's behavior lies between a solid-like and a liquidlike viscoelastic sample. The predominance of G" in HEC preparation indicates that this polymer dispersion behaves as a viscoelastic liquid.

The structured network created by the CBP explains why it was not possible to determine its ethanol content using alcoholmeter. As the resulting force from the equilibrium between gravity and buoyancy forces decreases, also does the force the alcoholmeter applies over the structure of the gel. Once this force becomes smaller than the gel's yield stress (minimum shear stress needed for the structure to breakdown), the alcoholmeter stops, preventing ethanol content determination. To remedy that, acidifying the CBP formulation results in the breakdown of the gelled structure, enabling the measurement.

In Figure $2 \mathrm{c}$ the dynamic viscosity $(\eta)$ is shown as a function of shear rate $(\dot{\gamma})$ to demonstrate the difference in viscosity between the center point formulas, for alcohol gel samples prepared as HPMC 1.00 wt.\%, HEC 1.50 wt. $\%$ and CBP 0.500 wt. $\%$.

It was possible to observe that the viscosity drop in CBP formulation was steeper than for cellulose derivatives, although it retains higher viscosity within the range tested. In contrast to measuring viscosity in a single shear rate of 20 RPM it was observed that viscosity varies largely as a function of shear rate even for HEC dispersion, which had the smallest angular coefficient, in which the viscosities are 371 and $109 \mathrm{mPa} \mathrm{s}$ at the smallest and largest shear rate, respectively. It is common to interpret the viscosity behavior through a Hershel-Buckley model regression with shear stress as a function of shear rate and described by equation 2 .

$$
\tau=\tau_{0}+\mathrm{K} \times \dot{\gamma}^{\mathrm{n}}
$$

In Table 3 are the values of the yield stress $\left(\tau_{0}\right)$ in $\mathrm{Pa}$, which represents the intercept of the regression, 

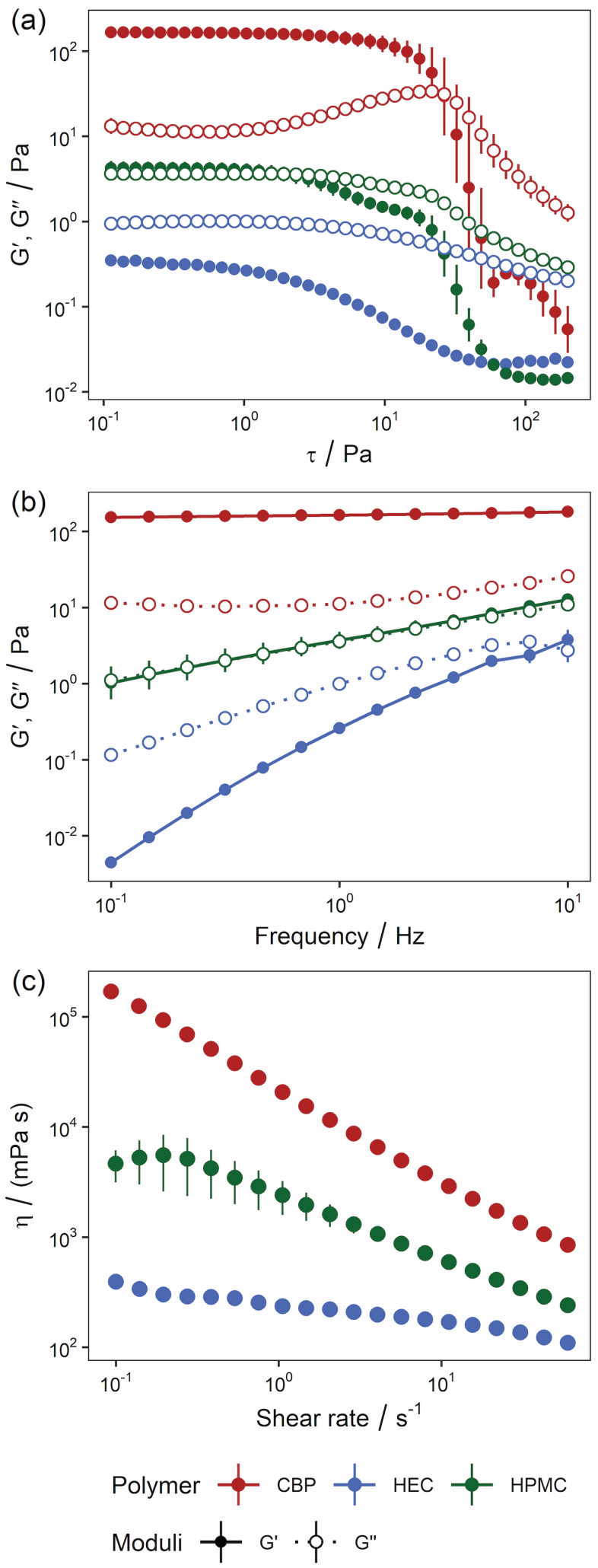

Figure 2. Rheological characterization of center point formulas by amplitude sweep (a), frequency sweep (b) and flow curve (c), the points and vertical lines represent mean and standard deviation between replicates, respectively, of formulations containing $70 \mathrm{wt} \%$ alcohol in gel, $1 \mathrm{wt} . \%$ of glycerin and $0.75 \mathrm{wt} . \%$ hydroxypropylmethylcellulose (HPMC), 0.75 wt.\% hydroxyethylcellulose (HEC) and 0.500 wt. $\%$ carbomer Carbopol $940^{\circ}$ (CBP). flow consistency index $(\mathrm{K})$ in $\mathrm{Pa}$ s associated to the fluid viscosity and the flow behavior index (n), which is dimensionless and indicates the viscosity dependence of the shear rate $(\dot{\gamma})$. Regression values were calculated for each of the center point dispersions.

The data shown in Table 3 confirm the information demonstrated by Figure 2a, the CBP gel had a larger yield stress $\left(\tau_{0}\right)$ in comparison to the other polymer dispersions $(P<0.001) . \tau_{0}$ was not different for HEC and HPMC samples $(p>0.05)$. Also, the consistence index $(\mathrm{K})$ was higher for CBP $(p<0.01)$ than for HMPC and HEC samples. There were no differences between the cellulose derivatives $(p>0.05)$. Comparing the index of flow (n), it was possible to observe that HEC sample was less dependent of shear rate than HPMC and CBP $(p<0.001)$. The rheological parameters demonstrated that the gel prepared with CBP may form a network that is harder to break hence prevent the alcoholmeter from reaching the necessary equilibrium to guarantee an accurate measurement.

Influence of polymer content and method in ethanol content determination

The influence of method (alcoholmeter and HR-MAS NMR) and amount of the polymer (wt.\%) in the determination of alcohol content in gelled alcohol samples were investigated. In these tests, formulations were prepared at $70.0 \mathrm{wt} . \%$ of ethanol and $1.00 \mathrm{wt} . \%$ of glycerin, and with different contents of the three investigated polymers, as shown in Table 4. The experiments were performed in triplicate and the HR-MAS NMR and alcoholmeter responses are also shown in Table 4.

The statistical comparison of the variances by the $F$-test between methods, considering the alcohol content measurements for samples without polymer, did not show a significant difference between them with a $95 \%$ of confidence level, since the $F$ value (equal to 15 ) was lower than the $F$ critical value for the triplicate (equal to 19).

Therefore, the two methods, alcoholmeter and HRMAS NMR, were capable to provide similar precision in absence of the polymer, despite the fact that the standard deviation value obtained by HR-MAS NMR was lower than alcoholmeter. Higher deviation values were expected for the alcoholmeter responses, due to the need to convert the alcohol content in ${ }^{\circ} \mathrm{GL}$ to wt. $\%$ at $15^{\circ} \mathrm{C}$, which introduces an error absent in the HR-MAS NMR determination. However, the deviations in the ethanol content (wt.\%) did not exceed $1.4 \%$, even for samples with high content of polymers, the interference in the determination of ethanol using alcoholmeter was expected, and includes the errors associated with the preparation of gels in triplicate. The 
Table 3. Flow curves regression parameters using a Hershel-Buckley model for the samples HPMC, HEC and CBP

\begin{tabular}{lcccc}
\hline Polymer & Replicate & $\tau_{0} / \mathrm{Pa}$ & $\mathrm{K} /(\mathrm{Pa} \mathrm{s})$ & $\mathrm{n}$ \\
\hline \multirow{2}{*}{ HPMC 0.75 wt.\% } & 1 & $-0.218 \pm 0.058$ & $2.523 \pm 0.056$ & $0.433 \pm 0.005$ \\
& 2 & $-0.477 \pm 0.017$ & $2.081 \pm 0.015$ & $0.470 \pm 0.002$ \\
\hline & 3 & $0.665 \pm 0.248$ & $2.349 \pm 0.239$ & $0.429 \pm 0.023$ \\
\hline HEC 0.75 wt.\% & 1 & $-0.079 \pm 0.017$ & $0.341 \pm 0.011$ & $0.730 \pm 0.008$ \\
& 2 & $-0.078 \pm 0.018$ & $0.339 \pm 0.011$ & $0.732 \pm 0.008$ \\
CBP 0.50 wt.\% & 3 & $-0.089 \pm 0.019$ & $0.348 \pm 0.012$ & $0.723 \pm 0.009$ \\
& 1 & $13.735 \pm 0.138$ & $4.931 \pm 0.131$ & $0.447 \pm 0.006$ \\
& 2 & $15.337 \pm 0.514$ & $7.797 \pm 0.510$ & $0.392 \pm 0.014$ \\
\end{tabular}

All the results are presented as average and standard error obtained from the curve regression. HPMC: hydroxypropylmethylcellulose; HEC: hydroxyethylcellulose; CBP: carbomer Carbopol $940^{\circ} ; \tau_{0}$ : yield stress; K: flow consistence index; n: flow index.

Table 4. Average viscosities and ethanol content measured by alcoholmeter and HR-MAS NMR methods for different polymer concentration

\begin{tabular}{|c|c|c|c|c|c|}
\hline \multirow{2}{*}{ Polymer } & \multirow{2}{*}{ Parameter } & \multicolumn{4}{|c|}{ Polymer content / wt.\% } \\
\hline & & 0 & 0.750 & 1.00 & 1.25 \\
\hline & $\eta^{\mathrm{a}} \pm \mathrm{SD}(\mathrm{n}=3) /(\mathrm{mPa} \mathrm{s})$ & $<1000$ & $2143 \pm 485$ & $3477 \pm 220$ & $5450 \pm 324$ \\
\hline & & 72.6 & 69.0 & 71.2 & 69.0 \\
\hline & ethanol alcoholmeter $/$ wt. $\%$ & 71.2 & 71.2 & 71.2 & 71.2 \\
\hline & & 72.6 & 70.1 & 73.5 & 70.1 \\
\hline \multirow[t]{10}{*}{ HPMC } & mean $\pm \mathrm{SD}(\mathrm{n}=3) / \mathrm{wt} . \%$ & $72.1 \pm 0.8$ & $70.1 \pm 1.1$ & $72.0 \pm 1.3$ & $70.1 \pm 1.1$ \\
\hline & & 70.6 & 71.5 & 71.3 & 70.8 \\
\hline & ethanol HR-MAS NMRc / wt.\% & 70.9 & 70.4 & 69.4 & 70.6 \\
\hline & & 71.0 & 72.3 & 70.8 & 70.2 \\
\hline & mean $\pm \mathrm{SD}(\mathrm{n}=3) / \mathrm{wt} . \%$ & $70.8 \pm 0.2$ & $71.4 \pm 1.0$ & $70.5 \pm 1.0$ & $70.5 \pm 0.3$ \\
\hline & & 0 & 0.750 & 1.50 & 2.00 \\
\hline & $\eta^{\mathrm{a}} \pm \mathrm{SD}(\mathrm{n}=3) /(\mathrm{mPa} \mathrm{s})$ & $<1000$ & $<1000$ & $2500 \pm 96$ & $6327 \pm 342$ \\
\hline & & 72.6 & 71.2 & 69.0 & 71.1 \\
\hline & ethanol alcoholmeter $/$ wt. $\%$ & 71.2 & 70.1 & 71.2 & 69.0 \\
\hline & & 72.6 & 71.2 & 69.0 & 71.1 \\
\hline \multirow[t]{10}{*}{ HEC } & mean $\pm \mathrm{SD}(\mathrm{n}=3) / \mathrm{wt} . \%$ & $72.1 \pm 0.8$ & $70.8 \pm 0.6$ & $69.7 \pm 1.3$ & $70.4 \pm 1.2$ \\
\hline & & 70.6 & 71.5 & 70.9 & 71.6 \\
\hline & ethanol HR-MAS NMR / wt.\% & 70.9 & 70.5 & 70.3 & 70.3 \\
\hline & & 71.0 & 71.3 & 71.0 & 71.0 \\
\hline & mean $\pm \mathrm{SD}(\mathrm{n}=3) / \mathrm{wt} . \%$ & $70.8 \pm 0.2$ & $71.1 \pm 0.5$ & $70.7 \pm 0.4$ & $71.0 \pm 0.7$ \\
\hline & & 0 & 0.350 & 0.500 & 0.650 \\
\hline & $\eta^{\mathrm{a}} \pm \mathrm{SD}(\mathrm{n}=3) /(\mathrm{mPa} \mathrm{s})$ & $<1000$ & $4397 \pm 90^{\mathrm{d}}$ & $7443 \pm 602^{\mathrm{d}}$ & $16200 \pm 522^{\mathrm{d}}$ \\
\hline & & 72.6 & 69.5 & 69.5 & 68.4 \\
\hline & ethanol alcoholmeter / wt.\% & 71.2 & 69.5 & 67.3 & 68.4 \\
\hline & & 72.6 & 68.4 & 67.3 & 69.5 \\
\hline \multirow[t]{5}{*}{$\mathrm{CBP}$} & mean $\pm \mathrm{SD}(\mathrm{n}=3) / \mathrm{wt} . \%$ & $72.1 \pm 0.8$ & $69.1 \pm 0.6$ & $68.0 \pm 1.3$ & $68.8 \pm 0.6$ \\
\hline & & 70.6 & 70.2 & 71.1 & 71.1 \\
\hline & ethanol HR-MAS NMR / wt.\% & 70.9 & 71.0 & 71.0 & 70.9 \\
\hline & & 71.0 & 71.0 & 71.4 & 71.4 \\
\hline & mean $\pm \mathrm{SD}(\mathrm{n}=3) / \mathrm{wt} . \%$ & $70.8 \pm 0.2$ & $70.7 \pm 0.5$ & $71.1 \pm 0.2$ & $71.1 \pm 0.2$ \\
\hline
\end{tabular}

${ }^{a} \eta$ : the viscosity at $20 \mathrm{rpm}$; bethanol determined using alcoholmeter, ${ }^{\mathrm{c}}$ ethanol determined using high resolution magic angle spinning nuclear magnetic resonance (HR-MAS NMR), dviscosities values obtained for CBP samples without acidification. For acidified CBP samples, analyzed by alcoholmeter and HR-MAS NMR methods, all viscosities were lower than $1000 \mathrm{mPa}$ s. HPMC: hydroxypropylmethylcellulose; HEC: hydroxyethylcellulose; CBP: carbomer Carbopol $940^{\circ}$. 
maximum deviation observed was lower than $1.75 \%$, which corresponds to $2.50 \%$ of acceptable variation in relation to the content of $70 \mathrm{wt} . \%$, as established by ANVISA for products with ethanol contents superior to $50 \mathrm{wt} \%$. The instrumental error associated to repeated measurements of the same sample was lower than $0.5 \mathrm{wt} . \%$, the nominal error of the alcoholmeter. ${ }^{6}$

A two-way ANOVA was performed in order to evaluate, simultaneously, the influence of HPMC, HEC and CBP concentration and the type of method used, NMR or alcoholmeter, in the quantification of the ethanol content in gelled samples as presented in the Table 5.

According to the two-way ANOVA parameters, neither the method nor the polymer content had a significant influence on ethanol concentration for HEC and HPMC formulations, with $95 \%$ of confidence level, as observed in Table 5, since no $F$ values overcome the respective $F$ critical value for the main effects. Additionally, no significant interaction effects were observed for these polymers, even with the viscosity (Table 4) being statistically different, according to one-way ANOVA, since the $F$ values for HPMC (161.2) and HEC (821.5) were higher than the $F$ critical value for two degrees of freedom and $95 \%$ of confidence level (4.07).

Noteworthy, it was not possible to determine the ethanol content using an alcoholmeter even for samples with the lowest concentration of CBP 0.350 wt.\%, without a previous acidification of the sample. As the average viscosity (4397 $\mathrm{mPa}$ s) of CBP at $0.350 \mathrm{wt} . \%$ was lower than the highest viscosity observed for HEC (2.00 wt.\% of HEC, $6327 \mathrm{mPa} \mathrm{s}$ ), and the quantification of ethanol was still possible for the cellulose derivative polymers, it reiterates the hypothesis that viscosity did not influenced the determination of ethanol content by the alcoholmeter method.

The flow index, viscosity dependence of shear rate, also appeared not to be determinant in the ethanol quantification in CBP samples, and the $\tau_{0}$ was the major factor associated. To reduce its influence, the CBP samples were acidified to depercolate the polymer in the gelled network, allowing ethanol determination using an alcoholmeter.

For CBP acidified formulations, according to the twoway ANOVA, both methods and polymer content affected the response, since all the $F$ values were greater than the respective $F$ critical. Moreover, the interaction effects were statistically significant for CBP-acidified samples. Hence, Tukey's test, with $95 \%$ of confidence level, was performed for the CBP responses, in order to investigate the significant differences among the samples.

According to the Tukey's test, there were no significant differences between the methods for ethanol determination in preparations without CBP. Nevertheless, for formulations containing $\mathrm{CBP}$, the averages obtained by the alcoholmeter method were different from the HR-MAS NMR average for the sample without polymer via the Tukey's test. However, this difference was not observed for the averages obtained by HR-MAS NMR for the same samples, indicating a strong influence of the determination method, i.e., the alcoholmeter method.

Table 5. Two-way ANOVA parameters for comparison of the content of the ethanol (wt.\%) estimated by alcoholmeter and HR-MAS NMR spectroscopy for $70 \mathrm{wt} . \%$ alcohol gel preparations with different polymer concentrations

\begin{tabular}{|c|c|c|c|c|c|c|}
\hline Polymer & Source & $\begin{array}{c}\text { Sum of squares } \\
\text { (SS) }\end{array}$ & $\begin{array}{l}\text { Degree of } \\
\text { freedom }(\mathrm{df})\end{array}$ & $\begin{array}{l}\text { Mean square } \\
\text { (MS) }\end{array}$ & $F$ value & $F$ critical \\
\hline \multirow{5}{*}{ HPMC } & main effect of the polymer content & 0.501 & 1 & 0.501 & 0.578 & 4.49 \\
\hline & main effect of the method & 4.91 & 3 & 1.635 & 1.88 & 3.24 \\
\hline & interaction effect & 8.31 & 3 & 2.770 & 3.19 & 3.24 \\
\hline & within & 13.9 & 16 & 0.868 & & \\
\hline & total & 27.6 & 23 & & & \\
\hline \multirow{5}{*}{ HEC } & main effect of the polymer content & 0.0741 & 1 & 0.0741 & 0.115 & 4.49 \\
\hline & main effect of the method & 5.08 & 3 & 1.69 & 2.62 & 3.24 \\
\hline & interaction effect & 4.63 & 3 & 1.54 & 2.39 & 3.24 \\
\hline & within & 10.3 & 16 & 0.646 & & \\
\hline & total & 20.1 & 23 & & & \\
\hline \multirow{5}{*}{ CBP } & main effect of the polymer content & 12.0 & 1 & 12.0 & 27.7 & 4.49 \\
\hline & main effect of the method & 22.3 & 3 & 7.44 & 17.1 & 3.24 \\
\hline & interaction effect & 16.9 & 3 & 5.64 & 13.0 & 3.24 \\
\hline & within & 6.94 & 16 & 0.434 & & \\
\hline & total & 58.2 & 23 & & & \\
\hline
\end{tabular}

HPMC: hydroxypropylmethylcellulose; HEC: hydroxyethylcellulose; CBP: carbomer Carbopol $940^{\circ}$. 
In addition, no significant differences $(p>0.05)$ in content of ethanol were observed between alcoholmeter and HR-MAS NMR methods comparing the CBP concentration of 0.65 wt.\% after acidification using $5 \mathrm{~mol} \mathrm{~L}^{-1} \mathrm{HCl}$ solution. In these experiments, the amount of $\mathrm{HCl}$ solution was reduced from $1.5 \mathrm{~g}$, as used in the Table 4, to $0.3 \mathrm{~g}$, increasing the $\mathrm{HCl}$ solution concentration in 5 times, and maintaining the same number of $\mathrm{HCl} \mathrm{mol}$ added to the alcohol in gel formulation. However, the ethanol concentration determined, using alcoholmeter, independent of the acidification, was the same, $68.7 \pm 0.6$ and $68.8 \pm 0.6$ wt. $\%(p>0.05)$.

Based on the information presented, it is strongly recommended, for the CBP samples, the use of lowest mass of $\mathrm{HCl}$ to obtain a pH ca. 3.3, measured after 1:10 dilution in water. The increase in the dilution during acidification, negatively affect the ethanol quantification. For example, if the $\mathrm{pH}$ was reduced to 2.4 , using $4.8 \mathrm{~g}$ of a $5 \mathrm{~mol} \mathrm{~L}^{-1} \mathrm{HCl}$ solution, the error in the ethanol quantification increases, $67.8 \pm 0.6$ wt. $\%$ (even after dilution correction). At this point the result were different from those measured using HR-MAS NMR $(p>0.05)$ as those observed for the use of $1 \mathrm{~mol} \mathrm{~L}^{-1} \mathrm{HCl}$ solution.

The results presented in the Table 4 were, in most of the cases, in the range of sample acceptability for alcohol gel commercialization by ANVISA. According to ANVISA ${ }^{6}$ the variation in the ethanol concentration is of $2.5 \%$ for $70 \mathrm{wt} . \%$ formulations, corresponding to a variation between 68.25 to 71.75 wt.\%, suggesting the alcoholmeter, even with the errors associated to CBP samples, can be applied in the routine quality control measurements.

To demonstrate that alcoholmeter could be used to ethanol quantification in more complex formulations as commercial samples, we randomly selected 8 samples of alcohol in gel obtained in the local market. The ethanol quantification was performed using HR-MAS NMR and alcoholmeter, and using a paired $t$-test, no differences was observed between the methods with $95 \%$ of confidence $\left(t_{\text {calculated }}<t_{\text {abulated }}\right)$ as presented in Table S1.

\section{Conclusions}

Alcoholmeter measurements of ethanol concentration was demonstrated to be a handy, faster, and cheaper method that can be promptly used to determine the alcohol content in hand sanitizers. For cellulose derivatives HEC and HPMC, direct measurements were possible; however, for CBP samples it was necessary to perform sample acidification. The results were comparable to NMR analysis and could be used as an accessible quality control measurement. Consequently, the alcoholmeter method proposed in this work is suitable for a preliminary analysis of the ethanol content in alcohol gel formulations as a reachable, faster, and cheaper method.

\section{Supplementary Information}

Supplementary data (Figures S1, S2, S3 and Table S1) are available free of charge at http://jbcs.sbq.org.br as PDF file.

\section{Acknowledgments}

This study was supported in part by the Coordenação de Aperfeiçoamento de Pessoal de Nível Superior (CAPES, grant code 001), Conselho Nacional de Desenvolvimento Científico e Tecnológico (CNPq, RAF projects 301172/2016-1; 430451/2018-0 and 303312/2019-0); Capes-PrInt (No. 88887.311748/2018-00) and the Financiadora de Estudos e Projetos (Finep No. 0463/20).

\section{Author Contributions}

Priscila L. S. Estevão was responsible for conceptualization, formal analysis, investigation, writing original draft; Franciely G. Colodi for formal analysis, investigation, writing original draft; Lucas C. L. do Carmo for formal analysis, investigation, writing original draft; Maria de Fátima C. dos Santos for formal analysis, investigation; Anderson Barison for investigation, writing-review and editing; Caroline R. M. D'Oc for investigation, writingreview and editing; Noemi Nagata for conceptualization, project administration, resources, writing-review and editing; Rilton A. de Freitas for conceptualization, project administration, resources, funding acquisition, writingreview and editing.

\section{References}

1. World Health Organization (WHO); WHO Director-General's Statement on IHR Emergency Committee on Novel Coronavirus (2019-nCoV), available at https://www.who.int/directorgeneral/speeches/detail/who-director-general-s-statement-onihr-emergency-committee-on-novel-coronavirus-(2019-ncov), accessed in February 2021.

2. Jefferson, T.; Spencer, E. A.; Plüddemann, A.; Roberts, N.; Heneghan, C.; Analysis of the Transmission Dynamics of COVID-19: An Open Evidence Review, available at https:// www.cebm.net/evidence-synthesis/transmission-dynamics-ofcovid-19/, accessed in February 2021.

3. Rutala, W. A.; Weber, D. J.; Guideline for Disinfection and Sterilization in Healthcare Facilities; Healthcare Infection 
Control Practices Advisory Committee (HICPAC), 2019, available at https://www.cdc.gov/infectioncontrol/guidelines/ disinfection/, accessed in February 2021.

4. Loison, P.; Gervais, P.; Perrier-Cornet, J.-M.; Kuimova, M. K.; Biochim. Biophys. Acta 2016, 1858, 2060.

5. Agência Nacional de Vigilância Sanitária (ANVISA); Brazilian Pharmacopoeia National Form, $2^{\text {nd }}$ ed.; ANVISA: Brasília, 2012.

6. Agência Nacional de Vigilância Sanitária (ANVISA); Resolução da Diretoria Colegiada (RDC) No. 59 Dispõe sobre Os Procedimentos e Requisitos Técnicos para a Notificação e o Registro de Produtos Saneantes e Dá outras Providências; Diário Oficial da União (DOU), Brasília, No. 244, de 22/12/2010, p. 80; Agência Nacional de Vigilância Sanitária (ANVISA); Resolução da Diretoria Colegiada (RDC) No. 7 Dispõe sobre Os Requisitos Técnicos para a Regularização de Produtos de Higiene Pessoal, Cosméticos e Perfumes e Dá outras Providências; Diário Oficial da União (DOU), Brasília, No. 29, de 11/02/2015, p. 39.

7. Vlaia, L.; Coneac, G.; Olariu, I.; Vlaia, V.; Lupuleasa, D. In Emerging Concepts in Analysis and Applications of Hydrogels; Majee, S. B., ed.; IntechOpen: London, UK, 2016, DOI: $10.5772 / 63953$.

8. Agência Nacional de Vigilância Sanitária (ANVISA); Resolução da Diretoria Colegiada (RDC) No. 350 Define Os Critérios $e$ os Procedimentos Extraordinários e Temporários para a Fabricação e Comercialização de Preparações Antissépticas ou Sanitizantes Oficinais Sem Prévia Autorização da Anvisa e Dá outras Providências, em Virtude da Emergência de Saúde Pública Internacional Relacionada ao SARS-CoV-2; Diário Oficial da União (DOU), Brasília, No. 55, de 20/03/2020, p. 154.

9. Zuriarrain, A.; Zuriarrain, J.; Villar, M.; Berregi, I.; Food Control 2015, 50, 758 .

10. Fonseca Jr., F. S.; e Brito, L. R.; Pimentel, M. F.; Leal, L. B.; J. Braz. Chem. Soc. 2020, 9, 1759.

11. Batista, L. R.; Antoniosi Filho, N. R.; J. Braz. Chem. Soc. 2020, 31, 394.

12. U.S. Department of Health and Human Services, Food and Drug Administration (FDA), Center for Drug Evaluation and Research (CDER); Temporary Policy for Manufacture of Alcohol for Incorporation into Alcohol-Based Hand Sanitizer Products During the Public Health Emergency (COVID-19); CDER: Rockville, USA, 2020.

13. Statistica, v. 9.1; MathWorks, Natick, USA, 2009.

14. Heyden, Y. V.; Nijhuis, A.; Smeyers-Verbeke, J.; Vandeginste, B. G. M.; Massart, D. L.; J. Pharm. Biomed. Anal. 2001, 24, 723.

15. Islam, M. T.; Rodríguez-Hornedo, N.; Ciotti, S.; Ackermann, C.; Pharm. Res. 2004, 21, 1192.

Submitted: November 20, 2020 Published online: February 19, 2021 